\title{
Níveis de inclusão e tempo de exposição da cana-de-açúcar ao óxido de cálcio sobre parâmetros digestivos e o desempenho de novilhas Nelore
}

\section{Douglas dos Santos Pina ${ }^{1^{*}}$, Sebastião de Campos Valadares Filho ${ }^{2}$, Luis Orlindo Tedeschi ${ }^{3}$, Analívia Martins Barbosa ${ }^{1}$, José Augusto Gomes Azevêdo ${ }^{4}$, Rilene Ferreira Diniz Valadares ${ }^{5}$, Natália Krish de Paiva Souza ${ }^{1}$, Mozart Alves Fonseca ${ }^{1}$}

\author{
1 Pós-graduação em Zootecnia - DZO/UFV. \\ 2 DZO/UFV e pesquisador do CNPq. \\ ${ }^{3}$ Texas A\&M University. \\ ${ }^{4}$ UESC - Ilheús. \\ ${ }^{5}$ DVT/UFV e pesquisadora do CNPq.
}

RESUMO - Avaliou-se nesta pesquisa o efeito da inclusão de óxido de cálcio (cal) e dos tempos de exposição da canade-açúcar à cal sobre o desempenho de novilhas Nelore, a digestibilidade dos componentes da dieta e a síntese de proteína microbiana ruminal (PBMic) e comparou-se o dióxido de titânio ao óxido crômico para estimar o consumo individual de concentrado. Utilizaram-se 30 fêmeas Nelore com aproximadamente 24 meses de idade e pesos médios de $285 \pm 31 \mathrm{~kg}$, alojadas em seis baias coletivas. As dietas foram arranjadas em esquema fatorial $3 \times 2$, com três níveis de cal (0; 0,5 ou $1 \%$ na matéria natural) e dois tempos de exposição (zero e três dias). Os tempos de exposição da cana-de-açúcar à cal não tiveram efeitos sobre as quantidades de nitrogênio microbiano, os consumos de matéria seca (MS) e orgânica (MO), proteína bruta (PB), total de nutrientes digestíveis e o ganho médio diário, porém influenciaram os consumos de extrato etéreo (EE), fibra em detergente neutro corrigida para cinzas e PB (FDNcp) e carboidratos não-fibrosos (CNF). Os níveis de cal influenciaram de forma linear decrescente os consumos de MO, FDNcp, CNF e NDT, e o GMD. Todavia, não foram observados efeitos dos indicadores (dióxido de titânio e óxido crômico) nem interações do tempo de exposição e do nível de cal sobre os consumos de MS, MO, PB, EE, FDNcp, CNF e NDT. Interações significativas do tempo de exposição e do nível de inclusão de cal foram observadas para as digestibilidades aparentes totais da MS, MO, PB e FDN e para o teor de NDT. Os indicadores dióxido de titânio e óxido crômico são igualmente efetivos para estimar os consumos individuais de concentrado de bovinos alimentados em grupo. O fornecimento de cana-de-açúcar armazenada durante três dias sem cal não altera o desempenho de novilhas em crescimento.

Palavras-chave: digestibilidade, dióxido de titânio, ganho de peso, óxido crômico

\section{Levels of inclusion and exposure time of sugar cane to calcium oxide on digestive parameters and performance of Nellore heifers}

\begin{abstract}
It was evaluated in this work the effects of levels of inclusion and exposure times of sugarcane to calcium oxide on the performance of Nellore heifers, digestibility of dietary components and synthesis of ruminal microbial protein and it was compared titanium dioxide to chromium oxide to estimate the individual intake of concentrate. It was used 30 Nellore females at approximately 24 months of age and average body weight of $285 \pm 31 \mathrm{~kg}$ and age of 24 months housed in six pens (50 $\mathrm{m}^{2}$ approximately), each one of them with five animals (feeding group). The diets were allocated in a $3 \times 2$ factorial arrangement, containing three levels of calcium oxide (0;0.5 and 1.0\% of sugarcane fresh matter) and two levels of exposure time ( 0 and 3 days). There were no effects of calcium oxide exposure time on the intake of microbial nitrogen, dry matter $(\mathrm{DM})$, organic matter $(\mathrm{OM})$, crude protein $(\mathrm{CP})$ and total digestible nutrients (TDN) and daily weight gain, but, it affected the intake of ether extract (EE), neutral detergent fiber corrected for ash and CP contamination (NDFcp), and nonfiber carbohydrate (NFC). The levels of whitewash decreased linearly the intake of OM, NDFap, NFC, and ADG. However, it was not observed effects of the markers (titanium dioxide and chromic oxide) nor interactions among exposure time and level of whitewash on intakes of DM, CP, EE, NDFap, NFC and TDN. Significant interactions between exposure time and level of inclusion of whitewash were observed for total aparent digestibility of DM, OM, and NDF and for content of TDN. Titanium oxide and chromic oxide are equally effective for estimating individual intakes of concentrate by bovine fed in group. Supply of sugar cane stored for three days without whitewash does not change performance of growing heifers.
\end{abstract}

Key Words: chromium, digestibility, markers, weight gain, and titanium

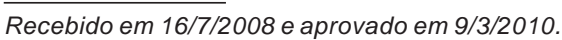

Correspondências devem ser enviadas para:douglaspina@yahoo.com.br

* Endereço atual: UFMT - Sinop - MT. 


\section{Introdução}

A utilização clássica da cana-de-açúcar é na forma in natura, cortada, desintegrada e fornecida diariamente para alimentação animal. Contudo, em grandes rebanhos, essa técnica torna-se o maior entrave para utilização desse volumoso, pois requer mão-de-obra diária para cortes, despalhamento, trituração e transporte. Assim, a possibilidade de conservação desse material para fornecimento aos animais por pelo menos 72 horas após o corte permitiria melhor logística para sua utilização e consequentemente redução dos custos associados ao corte, transporte e à desintegração.

A cana-de-açúcar, apesar de possuir interessantes características como volumoso, possui algumas restrições nutricionais, por exemplo: baixa concentração proteica e alta proporção de fibra com baixa digestibilidade. Contudo, apesar de sua grande capacidade de digestão de material fibroso, os animais ruminantes podem ser limitados nutricionalmente pelos componentes da dieta (Ortiz-Rubio et al., 2007).

A porção da fibra ingerida que é resistente à fermentação pelos microrganismos ruminais acumula-se no rúmen em relação à fração potencialmente fermentável (Allen \& Mertens, 1988) e tem efeito direto na redução do consumo de alimento e no desempenho dos animais. Assim, alternativas para aumentar a fração potencialmente digestível da fibra ou sua taxa de digestão podem ter impactos positivos sobre o consumo e o desempenho dos animais. Nesse contexto, agentes alcalinizantes, como o óxido de cálcio $(\mathrm{CaO})$, podem ser utilizados para melhorar a digestibilidade de resíduos agroindustriais, palhas e cana-de-açúcar in natura (Oliveira et al., 2002).

A avaliação da digestibilidade dos compontentes dietéticos é premissa básica para determinar os efeitos da adição de agentes alcalinizantes sobre a dieta. A técnica dos indicadores talvez seja a mais amplamente utilizada e aceita para essa finalidade (Valadares Filho et al., 2006a) e baseia-se na obtenção inicial de um parâmetro básico de indigestibilidade da dieta consumida e, posteriormente, do uso de artifícios indiretos para determinação da digestibilidade da dieta (Detmann et al., 2004).

Dessa forma, um experimento foi conduzido com o objetivo de avaliar o efeito da inclusão de cal e dos tempos exposição da cana-de-açúcar à cal sobre a digestibilidade aparente total e o consumo de componentes da dieta, estimados pela técnica dos indicadores externos (dióxido de titânio e o óxido crômico), a síntese microbiana ruminal e o desempenho de novilhas Nelores.

\section{Material e Métodos}

Foram utilizadas 30 fêmeas Nelores, com aproximadamente 24 meses de idade e pesos médios de $285 \pm 31 \mathrm{~kg}$. Os animais foram alojados em baias coletivas (aproximadamente $50 \mathrm{~m}^{2}$ ) contendo cinco animais por baia, com piso de concreto e providas de comedouros e de bebedouros coletivos.

O experimento foi conduzido em três períodos de 28 dias após um período de adaptação de 14 dias, nos quais os animais foram pesados para ajuste da quantidade de concentrado fornecida ao grupo, sendo o mesmo procedimento realizado no início e final de cada período experimental. As dietas foram constituídas por $80 \%$ de volumoso (cana-deaçúcar adicionada de 1\% de uréia e sulfato de amônia (9:1) na base da matéria natural (MN) imediatamente antes de seu fornecimento) e $20 \%$ de concentrado na base da MS. As dietas foram arranjadas em esquema fatorial $3 \times 2$, sendo três níveis de inclusão da cal ( 0 ; 0,5 ou $1 \%$ na base da MN) e dois tempos de armazenamento da cana-de-açúcar (zero e três dias).

Todos os dias antes da alimentação dos animais, aproximadamente $900 \mathrm{~kg}$ de cana-de-açúcar in natura eram desintegrados, sendo os mesmos divididos em 6 pilhas de igual tamanho (150 kg) e espalhados manualmente. Depois desse procedimento, o óxido de cálcio era pesado (0, 750 e $1500 \mathrm{~g})$ e adicionado as pilhas de cana-deaçúcar, a quais eram misturadas manualmente (aproximadamente 5 minutos) de modo a permitir uma homegeinização do material. As pilhas de cana-de-açúcar expostas a um tempo maior de exposição ao óxido de cálcio (24, 48 e 72 horas) até o fornecimento aos animais, eram armazenadas em um galpão de modo a impedir a exposição das mesmas ao sol e a chuva. As dietas foram balanceadas de acordo com Valadares Filho et al. (2006b), para conter aproximadamente $11,5 \%$ de $\mathrm{PB}$.

Nos três períodos experimentais, a alimentação foi oferecida ad libitum duas vezes ao dia, sempre às 8 e 16 h, na forma de dieta completa, permitindo-se sobras de, no máximo, $10 \%$ da matéria natural oferecida. O consumo diário foi mensurado pela diferença entre o fornecido e as sobras, sendo que amostras diárias do alimento fornecido e das sobras foram coletadas durante todos os períodos e ao final de cada semana foi feita uma amostra composta representativa por grupo de alimentação, sendo esta, armazenada em saco plástico e congelada a $-20^{\circ} \mathrm{C}$, para posteriormente ser analisada.

O consumo individual foi estimado segundo Valadares Filho et al. (2006a), utilizando a LIPE fornecida na quantidade 
Tabela 1- Composição bromatológica das dietas experimentais

\begin{tabular}{|c|c|c|c|c|c|c|}
\hline & \multicolumn{6}{|c|}{ Tempo de armazenamento (dias) } \\
\hline & \multicolumn{3}{|c|}{0} & \multicolumn{3}{|c|}{3} \\
\hline & \multicolumn{3}{|c|}{ Dose de cal (\% da MN) } & \multicolumn{3}{|c|}{ Dose de cal (\% da MN) } \\
\hline & 0 & 0,5 & 1,0 & 0 & 0,5 & 1,0 \\
\hline \multicolumn{7}{|c|}{ Ingredientes no concentrado (\% MN) } \\
\hline Fubá de milho & 76,67 & 76,67 & 76,67 & 76,67 & 76,67 & 76,67 \\
\hline Farelo de soja & 20,00 & 20,00 & 20,00 & 20,00 & 20,00 & 20,00 \\
\hline Mistura mineral & 3,30 & 3,30 & 3,30 & 3,30 & 3,30 & 3,30 \\
\hline \multicolumn{7}{|l|}{ Composição química das dietas } \\
\hline Matéria seca (\%) & 40,6 & 41,5 & 42,7 & 39,6 & 42,5 & 43,6 \\
\hline Matéria orgânica ${ }^{1}$ & 95,9 & 95,9 & 93,9 & 96,4 & 95,9 & 93,7 \\
\hline Proteína bruta ${ }^{1}$ & 11,7 & 11,4 & 11,0 & 12,1 & 11,9 & 11,3 \\
\hline Extrato etéreo ${ }^{1}$ & 2,06 & 2,04 & 2,08 & 2,20 & 2,24 & 2,25 \\
\hline $\mathrm{FDNcp}^{1}$ & 40,5 & 39,1 & 38,4 & 43,7 & 42,0 & 40,3 \\
\hline Carboidratos não-fibrosos ${ }^{1}$ & 41,6 & 43,5 & 42,9 & 38,1 & 39,8 & 40,2 \\
\hline Cálcio $^{1}$ & 0,36 & 1,34 & 2,36 & 0,36 & 1,34 & 2,36 \\
\hline
\end{tabular}

${ }^{1}$ Proporção na matéria seca da dieta.

Matéria mineral: Ca - 240,00 g; P - 174,00 g; Zn - 5.270,00 mg; Mn - 2.000,00 mg; F - 1.740,00 mg; Cu - 1.250,00 mg; Co - 100,00 mg; I - 90,00 mg; e Se - 15,00 mg. Quantidade por kg de mistura mineral.

FDNcp = fibra em detergente neutro corrida para cinzas e proteína.

de 500 mg por dia como indicador externo, administrada por via esofágica para estimar a excreção de MS fecal, iniciando-se o fornecimento três dias antes do início das coletas de fezes e terminando no último dia de coleta. Os indicadores externos fornecidos no concentrado para estimar o consumo individual de matéria seca do concentrado (Cc; equação 1) foram o óxido crômico e o dióxido de titânio (Cr e Ti, respectivamente; 0,3\% na MN do concentrado) e o indicador interno utilizado para estimar o consumo de matéria seca de volumosos (Cv; equação 2) foi a fibra em detergente neutro indigestível (FDNi).

$$
C c=\frac{E F *[\text { Ind fezes }]}{[\text { Ind no } C c]}
$$

em que: $C c=$ consumo de MS do concentrado; $[$ Ind $]=$ concentração do indicador ( $\mathrm{Ti}$ ou $\mathrm{Cr}$ ) no concentrado ou nas fezes.

$C v=\frac{E F *[\text { FDNifezes }]-C C *[\text { FDNi concentrado }]}{[\text { FDNi volumoso }]}$

em que: $C v$ = consumo de MS do volumoso; $[F D N i]=$ concentração da FDNi.

As amostras de fezes foram coletadas uma vez ao dia (durante cinco dias), simultaneamente, em intervalos de 22 horas, iniciando-se às $16 \mathrm{~h}$ no primeiro dia e terminando às $8 \mathrm{~h}$ no último. As análises de MS, MO, nitrogênio total, EE, FDN e lignina foram realizadas conforme procedimento descrito por Silva \& Queiroz (2002). As determinações de FDN foram realizadas de acordo com o método de (Ferreira \& Mertens, 2007) utilizando-se o extrator ANKOM200 (Ankom Technology Corp., Fairport, NY, USA).
As amostras de fezes e sobras foram submetidas à análise de teor de cromo em espectrofotômetro de absorção atômica, conforme método descrito por Willians et al. (1962) e de titânio, por colorimetria conforme método descrito por Myers et al. (2004). Os teores de NDT foram determinados segundo a equação proposta pelo NRC (2001): $\mathrm{NDT}=\mathrm{PBd}+2,25 \mathrm{EEd}+\mathrm{FDN}_{\mathrm{cp}} \mathrm{d}+\mathrm{CNFd}$, em que PBd é PB digestível; EEd, o EE digestível; $F D N_{c p}$ d, a $\mathrm{FDN}_{\mathrm{cp}}$ digestível e CNFd, os CNF digestíveis.

Aproximadamente na metade do segundo período experimental, às $12 \mathrm{~h}$, foram coletadas amostras spot de urina de todos os animais. Alíquotas de $10 \mathrm{~mL}$ de urina foram diluídas em $40 \mathrm{~mL}$ de ácido sulfúrico 0,036 N e congeladas a $-20^{\circ} \mathrm{C}$ para análises e determinação de derivados de purinas (ácido úrico e alantoína) e creatinina (Valadares et al., 1997).

A alantoína foi determinada na amostra spot de urina diluída utilizando-se o método colorimétrico de Fujihara et al. (1987), descrito por Chen \& Gomes (1992). A creatinina e o ácido úrico foram determinados na amostra spot de urina diluída, utilizando-se kits comercias (Labtest Diagnóstica S.A.). O volume urinário médio diário foi obtido, dividindo-se a excreção total de creatinina (concentração de creatinina em $\mathrm{mg} / \mathrm{kg}$ de PV multiplicada pelo peso corporal) pela concentração de creatinina na amostra spot de urina, sendo o valor de $27,11 \mathrm{mg} / \mathrm{kg}$ de PV de creatinina, utilizado para a estimativa do volume urinário (Barbosa et al., 2006). A excreção total de derivados de purina foi calculada pela soma das quantidades de alantoína e ácido úrico excretadas na urina, expressas em mmol/dia. 
As purinas absorvidas (X, mmol/dia) foram calculadas a partir da excreção de derivados de purinas (Y, mmol/dia), por intermédio da equação $\mathrm{Y}=0,85 \mathrm{X}+0,170 \times \mathrm{PV}^{0,75}$, em que 0,85 é a recuperação das purinas absorvidas como derivados de purina e 0,170 PV ${ }^{0,75}$ é a contribuição endógena para a excreção de purinas (Osuji et al., 1996). A síntese ruminal de compostos nitrogenados ( $\mathrm{Y}$, g de $\mathrm{N} / \mathrm{dia}$ ) foi calculada em função das purinas absorvidas (X, mmol/dia), utilizando-se a equação de Chen \& Gomes (1992): $Y=70 X /$ ( 0,83 x 0,134 x 1000), em que 70 é o conteúdo de $N$ nas purinas (mg de $\mathrm{N} / \mathrm{mmol}$ ); 0,116 a relação $\mathrm{N}$-purina: $\mathrm{N}$-total nas bactérias (Valadares et al., 1999); e 0,83 a digestibilidade das purinas microbianas.

O experimento foi analisado segundo delineamento inteiramente casualizado, em esquema fatorial $3 \times 2$, sendo três níveis de inclusão da cal e dois tempos de exposição à cal. O efeito de indicador foi avaliado no esquema de parcela subdividida, sendo as parcelas compostas pelos tratamentos (três níveis de cal e dois TE) e as subparcelas compostas pelos indicadores ( $\mathrm{Ti}$ ou $\mathrm{Cr}$ ). Os resultados foram avaliados por intermédio do procedimento PROC MIXED SAS (SAS, 1999), adotando-se 0,05 como nível crítico de probabilidade para o erro tipo 1 , sendo as comparações entre médias realizadas através de contrastes ortogonais e pelo test “t” (Kaps \& Lamberson, 2004).

\section{Resultados e Discussão}

Não foram observados efeitos $(\mathrm{P}>0,05)$ dos tempos de exposição da cana-de-açúcar (zero ou três dias) sobre os consumos de MS, MO, PB e NDT. Porém, após três dias de armazenamento, os consumos de EE e FDNcp aumentaram e os de CNF diminuíram $(\mathrm{P}<0,05)$. Também não foram observados efeitos $(\mathrm{P}>0,05)$ dos indicadores (Ti e Cr), nem interações entre os níveis de inclusão da cal e os tempos de armazenamento $(\mathrm{P}>0,05)$ sobre as estimativas de consumos de MS, MO, PB, EE, FDNcp, CNF e NDT (Tabela 2).

O aumento no consumo de FDNcp e a redução do consumo dos CNF observados durante o armazenamento da cana-de-açúcar por três dias, pode ser devido à fermentação da cana-de-açúcar ocorrida durante o seu armazenamento, o que é refletido na composição química das dietas (Tabela 1).

A ausência de efeito do tempo de exposição sobre os consumos de MS, MO, PB e NDT está de acordo com as observações de Pina et al. (2010), os quais, trabalharam com novilhas Nelore fistuladas no rúmen e no abomaso e não observaram efeitos dos tempos de exposição da cana-de-açúcar à cal sobre os consumos de MS, MO, PB, EE, FDNcp, CNF e NDT. Pontes (2007), trabalhou com ovinos alimentados com cana-de-açúcar acrescida de cal (0; 0,5 e 1,0\% na base da MN) com tempos de exposição de 0 e 24 horas, não observou efeito desses tempos, nem da interação entre os níveis de inclusão de cal e os tempos de exposição sobre o consumo dos nutrientes. Minor \& Hovell (1978), avaliaram o efeito de dois perídos de exposição (0 e 24 horas) da cana-de-açúcar ao hidróxido de sódio (0, 30 e 60 g/kg de MN), e também não observaram efeito $(\mathrm{P}>0,05)$ dos níveis de inclusão do hidróxido de sódio e os tempos de exposição em relação ao consumo de MS dos animais, que variou de 2,80 a 3,88 kg/dia.

Tabela 2 - Consumo dos componentes da dieta por novilhas Nelore em crescimento

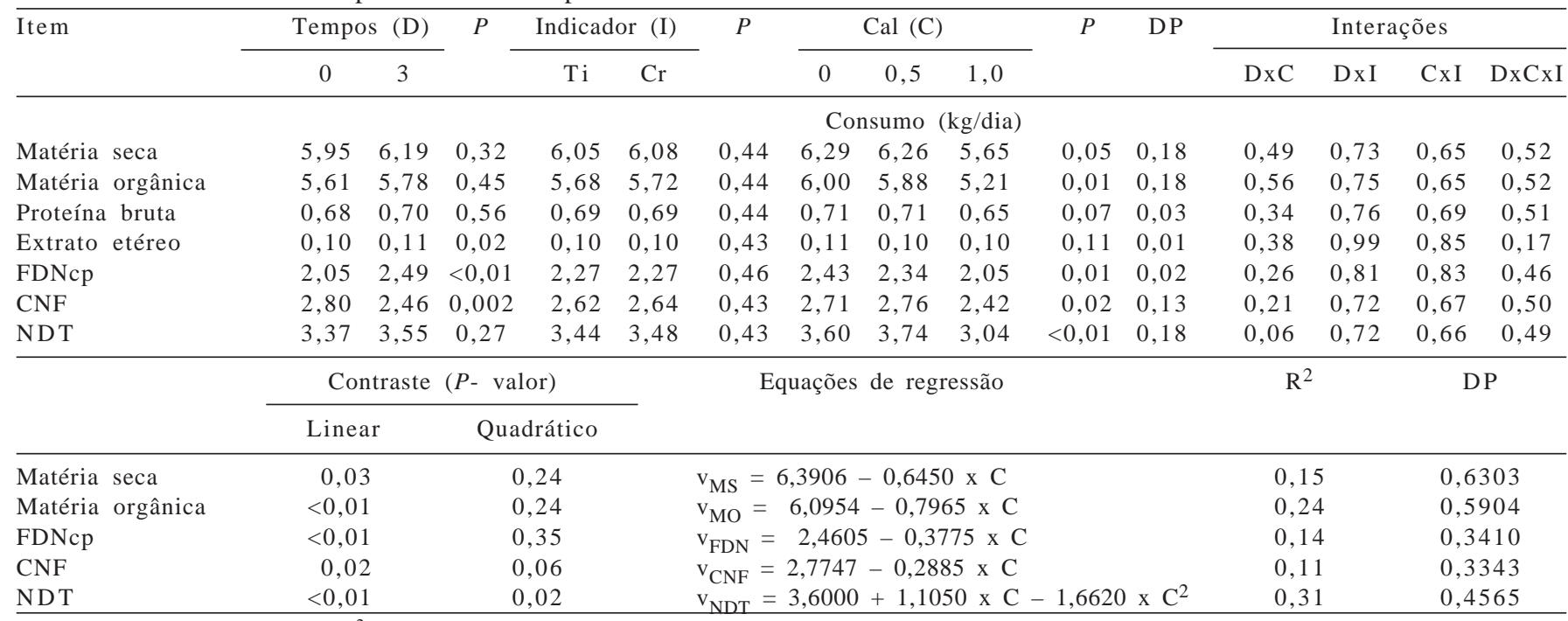

$\mathrm{DP}=$ desvio-padrão; $P=$ valor $P$ e $\mathrm{R}^{2}=$ coeficiente de determinação das equaçoes lineares ou quadráticas.

$\mathrm{Ti}$ = dióxido de titânio; $\mathrm{Cr}$ = óxido crômico.

FDNcp = fibra insolúvel em detergente neutro corrigida pra cinzas e proteína bruta; CNF = carboidratos não-fibrosos; NDT = total de nutrientes digestívies . 
Dessa forma, a conservação desse material para fornecimento aos animais por pelo menos 72 horas após o corte não influencia o consumo de componentes da dieta, mas permite melhor logística e redução dos custos associados com corte, transporte e trituração do material. Segundo Santos et al. (2005), a única vantagem da utilização da cal como aditivo à cana-de-açúcar é a possibilidade de armazenamento da mesma já desintegrada. Uma vez que, ocorrem perdas de matéria seca tanto na cana-deaçúcar in natura quanto na hidrolisada, sendo esta perda menor na cana hidrolisada com 1,0 e 1,5\% de cal, quando armazenada por até dez dias já desintegrada.

Os níveis de inclusão da cal influenciaram $(\mathrm{P}<0,01)$ de forma linear decrescente os consumos de MS, MO, FDNcp, CNF. Mas não inlfuenciaram os consumos de PB e EE (Tabela 2). Esses resultados são distoantes dos obtidos por Pina et al. (2010) que observaram efeito linear crescente do nível de inclusão do óxido de cálcio sobre os consumos de MS, MO e CNF. Losada et al. (1977), estudaram o efeito da inclusão de quatro níveis de hidróxido de sódio (0, 2, 4 e 6\% MS) na cana, e encontraram tendência de aumento linear no consumo de acordo com o nível de hidróxido de sódio (6,82; 7,66; 7,80 e 8,12 kg de MS por dia, para os níveis de 0, 2, 4 e 6\%, respectivamente). O consumo de NDT apresentou comportamento quadrático, sendo estimado consumo máximo com $0,33 \%$ de cal (Tabela 2).

Assim como em relação às estimativas do consumo, não foram observadas influências $(P>0,05)$ dos indicadores sobre as estimativas de digestibilidade da MS, MO, PB, EE, FDNcp e CNF e sobre o teor de NDT (Tabela 3). De forma semelhante aos resultados do presente experimento, Titgemeyer et al. (2001) não observaram diferença entre o dióxido de titânio e o óxido de crômico, quando utilizados para estimar a digestiblidade total da MS.

Pina et al. (2009) avaliaram o efeito dos níveis de concentrado (20 e 40\% MS da dieta) e de proteína não degradada no rúmen (PNDR; 25 e 40\% PB) em dietas à base de silagem de milho, em novilhas Nelore, e não observaram diferenças entre os indicadores externos quando utilizados para estimar os fluxos de matéria seca (MS) fecal, ileal e abomasal.

Não foi observada interação significativa entre o tempo de exposição e o nível de inclusão de cal para o ganho de peso $(\mathrm{P}>0,05)$. O tempo de exposição da cana-de-açúcar à cal não influenciou o desempenho dos animais $(\mathrm{P}>0,05)$, contudo o nível de inclusão de cal reduziu linearmente $(\mathrm{P}<0,05)$ o ganho de peso dos animais. Esse efeito da cal sobre o desempenho dos animais pode ser consequência do efeito da mesma sobre os consumos de MS e MO, que reduziram linearmente $(\mathrm{P}<0,05)$ com a inclusão de cal (Tabela 2).

A utilização da cana-de-açúcar como volumoso exclusivo (80\% da MS dietética) acrescida com quatro diferentes suplementos concentrados (20\% na base da MS dietética) foi avaliada por Alleoni et al. (2006), os quais observaram variação na ingestão de MS de 4,46 a 5,97 kg/dia e no ganho de peso médio diário dos animais de 320 a 621 g. Esses valores são próximos da variação encontrada no presente experimento, que foi de 5,65 a 6,29 kg/dia e de 336 a $683 \mathrm{~g} /$ dia, para o consumo de MS dietética e o ganho de peso médio diário, respectivamente (Tabelas 2 e 3).

Alvarez et al. (1977) alimentaram novilhos com cana-deaçúcar imediatamente após o corte ou após 24 horas de armazenamento, relataram redução no ganho de peso médio diário, que variou de 795 a 658 g/dia. Entretanto, não foi

Tabela 3 - Digestibilidades aparentes totais dos componentes da dieta e desempenho de novilhas Nelore em crescimento

\begin{tabular}{|c|c|c|c|c|c|c|c|c|c|c|c|c|c|c|c|}
\hline \multirow[t]{2}{*}{ Item } & \multicolumn{2}{|c|}{ Tempos (D) } & \multirow[t]{2}{*}{$P$} & \multicolumn{2}{|c|}{ Indicador (I) } & \multirow[t]{2}{*}{$P$} & \multicolumn{3}{|c|}{ Cal (C) } & \multirow[t]{2}{*}{$P$} & \multirow[t]{2}{*}{ DP } & \multicolumn{4}{|c|}{ Interações } \\
\hline & 0 & 3 & & $\mathrm{Ti}$ & $\mathrm{Cr}$ & & 0 & 0,5 & 1,0 & & & DxC & DxI & CxI & $\mathrm{DxCxI}$ \\
\hline \multicolumn{16}{|c|}{ Digestibilidade aparente total (\%) } \\
\hline Matéria seca & 54,91 & 57,10 & 0,02 & 55,85 & 56,16 & 0,37 & 56,69 & 58,09 & 53,24 & $<0,01$ & 1,33 & $<0,01$ & 0,62 & 0,77 & 0,61 \\
\hline Matéria orgânica & 57,94 & 59,32 & 0,10 & 58,51 & 58,75 & 0,52 & 58,92 & 60,74 & 56,23 & $<0,01$ & 1.41 & $<0,01$ & 0,39 & 0,80 & 0,73 \\
\hline Proteína bruta & 56,15 & 66,50 & $<0,0001$ & 61,12 & 61,53 & 0,44 & 60,25 & 63,83 & 59,90 & 0,06 & 2,00 & $<0,01$ & 0,62 & 0,66 & 0,55 \\
\hline Extrato etéreo & 68,70 & 71,86 & 0,32 & 69,91 & 70,65 & 0,15 & 67,04 & 70,71 & 73,08 & 0,30 & 1,95 & 0,44 & 0,29 & 0,64 & 0,55 \\
\hline FDNcp & 21,86 & 35,65 & $<0,0001$ & 28,70 & 28,81 & 0,46 & 29,74 & 30,67 & 25,85 & 0,09 & 0,53 & 0,01 & 0,63 & 0,74 & 0,64 \\
\hline Carboidratos não-fibrosos & 84,42 & 80,60 & $<0,01$ & 82,43 & 82,59 & 0,40 & 83,12 & 85,04 & 79,37 & $<0,01$ & 0,70 & 0,24 & 0,95 & 0,90 & 0,66 \\
\hline \multirow[t]{3}{*}{ Nutrientes digestíveis totais } & 56,38 & 56,64 & 0,36 & 56,64 & 56,93 & 0,36 & 57,09 & 59,57 & 53,69 & $<0,01$ & 1.19 & $<0,01$ & 0,62 & 0,78 & 0,60 \\
\hline & & & & & & & & & & & & \multicolumn{4}{|c|}{ Contraste $(P$ - valor $)$} \\
\hline & & & & & & & & & & & & & Linear & Quc & adráticc \\
\hline Ganho médio diário (kg) & 0,458 & 0,596 & 0,11 & - & - & - & 0,683 & 0,561 & 0,336 & 0,01 & 0,23 & 0,69 & 0,01 & & 0,56 \\
\hline
\end{tabular}

$\mathrm{DP}=$ desvio-padrão e $P=$ valor $P$.

Ti = dióxido de titânio; $\mathrm{Cr}$ = óxido crômico.

FDNcp = fibra insolúvel em detergente neutro corrigida pra cinzas e proteína bruta. 
observado efeito significativo do período de armazenamento sobre o consumo, que variou de 6,27 a 6,17 kg de MS/dia. Dessa forma, o efeito no desempenho foi atribuído a menor eficiência de utilização do alimento ingerido, quando o mesmo foi pré-fermentado antes do fornecimento aos animais.

Foram observadas interações significativas $(\mathrm{P}<0,05)$ entre o tempo de exposição e o nível de inclusão de cal para as estimativas de digestibilidade aparente total da MS, MO, PB e FDNcp e para o teor de NDT (Tabela 3). Não foi observado efeito dos tempos de exposição nem dos níveis de inclusão de cal sobre o coeficiente de digestibilidade aparente total do EE $(\mathrm{P}>0,05)$. Contudo, o coeficiente de digestibilidade aparente total do CNF foi reduzido $(\mathrm{P}<0,01)$ de 84,42 para 80,60\% na dieta contendo cana-de-açúcar armazenada durante três dias. O nível de inclusão de cal influenciou quadraticamente $(\mathrm{P}<0,01)$ o coeficiente de digestibilidade aparente total dos carboidratos não-fibrosos (Tabela 4).

O aumento do tempo de exposição da cana-de-açúcar de 0 para 3 dias influenciou positivamente os coeficientes de digestibilidade aparente total da MS, MO, PB e FDN e os teores de NDT dentro dos níveis de inclusão de 0,5 e 1,0\% de cal. Contudo, na ausência de cal (nível zero de inclusão), o aumento no tempo de armazenamento reduziu a digestibilidade da $\mathrm{MO}$ e o teor de NDT, mas não foram observados efeitos do tempo de exposição dentro do nível zero de inclusão de cal para a digestibilidade aparente total da MS, PB e FDNcp (Tabela 4).

Analisando o efeito da inclusão de cal dentro de cada tempo de armazenamento, observa-se que a inclusão reduziu linearmente $(\mathrm{P}<0,01)$ os coeficientes de digestibilidade aparente total da MS, MO, PB e FDNcp e o teor de NDT das dietas dentro do tempo de exposição zero (Figura 1). Todavia,

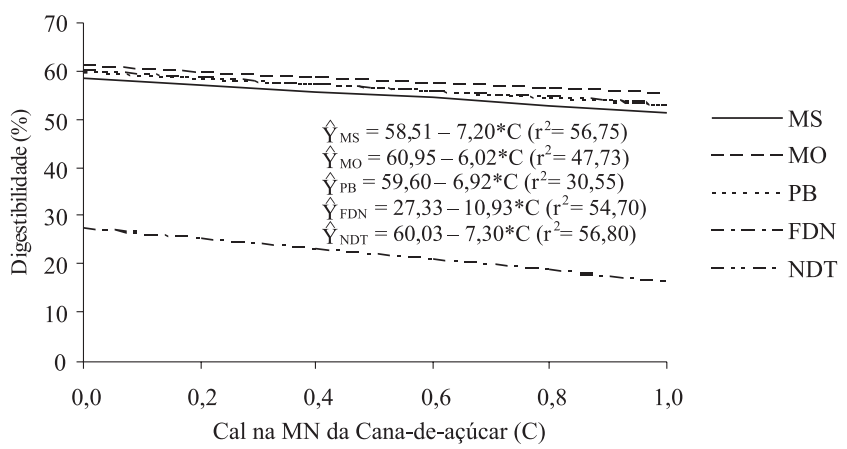

Figura 1 - Relação entre o nível de inclusão de cal (\%MN) e a digestibilidade aparente total da MS, MO, PB, $\mathrm{FDN}_{\mathrm{cp}}$ e o NDT dentro do tempo de armazenamento de zero dias.

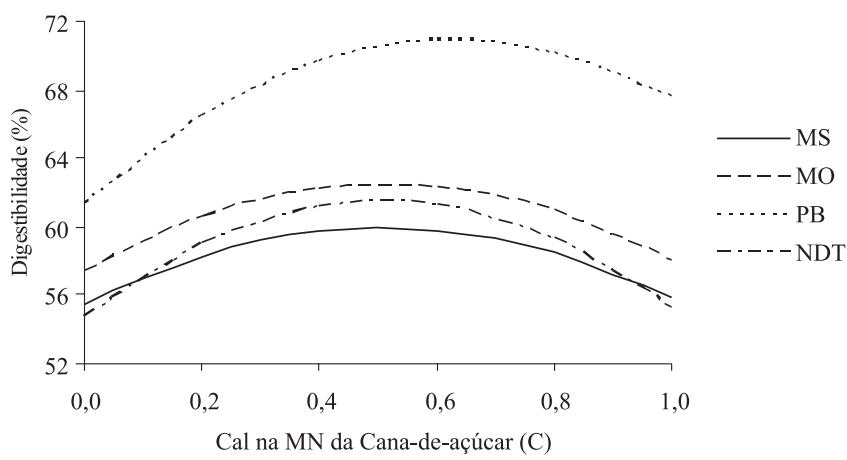

Figura 2 - Relação entre o nível de inclusão de cal (\%MN) e a digestibilidade aparente total da MS, MO, PB e o NDT dentro do tempo de armazenamento de três dias.

comportamento quadrático $(\mathrm{P}<0,01)$ foi observado para os coeficientes de digestibilidade da MS, MO, PB e para o teor de NDT das dietas em relação ao nível de inclusão de cal após três dias de armazenamento da cana-de-açúcar (Figura 2). Os pontos de máximo para os coeficientes de digestibilidades aparente total da MS, MO, PB e do teor de

Tabela 4 - Interação da inclusão de cal e dos tempos de exposição da cana-de açúcar à cal na digestibilidade aparente total dos componentes da dieta

\begin{tabular}{|c|c|c|c|c|c|c|}
\hline \multirow[t]{2}{*}{ Item } & \multirow[t]{2}{*}{ Tempo de exposição (dias) } & \multicolumn{3}{|c|}{ Dose de cal (\% da MN) } & \multicolumn{2}{|c|}{ Contraste $(P-$ valor $)$} \\
\hline & & 0 & 0,5 & 1,0 & Linear $\mathrm{C} / \mathrm{D}$ & Quadrático C/D \\
\hline \multirow[t]{2}{*}{ Matéria seca } & 0 & 57,85 & $56,23 a$ & $50,65 a$ & $<0,0001$ & 0,13 \\
\hline & 3 & 55,52 & $59,96 b$ & $55,83 b$ & 0,84 & $<0,01$ \\
\hline \multirow[t]{2}{*}{ Matéria orgânica } & 0 & $60,41 \mathrm{a}$ & $59,03 a$ & $54,39 a$ & $<0,01$ & 0,20 \\
\hline & 3 & $57,44 b$ & $62,45 b$ & $58,07 b$ & 0,66 & $<0,01$ \\
\hline \multirow[t]{2}{*}{ Proteína bruta } & 0 & 59,11 & $57,14 \mathrm{a}$ & $52,20 \mathrm{a}$ & $<0,01$ & 0,49 \\
\hline & 3 & 61,39 & $70,53 b$ & $67,60 \mathrm{~b}$ & 0,02 & $<0,01$ \\
\hline \multirow[t]{2}{*}{ FDNcp } & 0 & 26,81 & $22,88 \mathrm{a}$ & $15,89 a$ & $<0,01$ & 0,58 \\
\hline & 3 & 32,67 & $38,46 b$ & $35,81 b$ & 0,33 & 0,13 \\
\hline \multirow[t]{2}{*}{ Nutrientes digestíveis totais } & 0 & 59,39 & $578,66 \mathrm{a}$ & $52,10 a$ & $<0,0001$ & 0,15 \\
\hline & 3 & 54,79 & $61,47 b$ & $55,29 b$ & 0,74 & $<0,0001$ \\
\hline
\end{tabular}

* Medias de dias dentro do mesmo nível de cal seguidas por letras diferentes, diferem pelo teste $\mathrm{t}(P<0,05)$

C/ D corresponde ao efeito do nível de cal (0; 0,5 e 1,0\% MN da cana-de-açúcar) dentro do tempo de exposição (0 ou 3 dias).

FDNcp = fibra insolúvel em detergente neutro corrigida pra cinzas e proteína bruta. 
NDT foram obtidos com um nível de inclusão de 0,51; 0,52; 0,63 e $0,51 \%$ de cal na MN da cana-de-açúcar.

O efeito do perído de exposição ( 0 e 24 horas) da canade-açúcar ao hidróxido de sódio (0, 30 e 60 g/kg de MN) sobre o coeficiente de digestibilidade aparente total da MS foi estudado por Minor \& Hovell (1978), o quais não observaram efeito significativo dos tratamentos em relação ao mesmo, o qual variou de 54,30 a 59,7\%. Alleoni et al. (2006) avaliaram a utilização da cana-de-açúcar como volumoso exclusivo (80\% na base da MS dietética) acrescida de quatro suplementos concentrados (20\% na base da MS dietética) e observaram variação na digestibilidade aparente total da MS de 58,55 a 64,16\% e no teor de NDT de 63,12 a $66,04 \%$. Os valores encontrados neste experimento foram próximos, uma vez que a digestibilidade aparente total da MS variou de 50,65 a 59,96\% e o teor de NDT de 52,10 a 61,47\% em relação ao nível de inclusão, independentemente do tempo de exposição. Todavia, são inferiores aos valores relatados por Preston (1977), de 66,70 a 68,20\% para canade-açúcar triturada em pedaços de aproximadamente 20; 7,5; e 3,5 mm.

Diante do exposto, pode-se inferir que o nível de inclusão de cal afeta positivamente a digestibilidade dos componentes da dieta, quando se permite um tempo de exposição de três dias à mesma, de modo que sua ação hidrolítica possa aumentar a disponibilidade dos nutrientes. Já a inclusão de cal na cana-de-açúcar para o fornecimento imediato aos animais, influenciou de maneira negativa a disponibilidade e o consumo de alguns componentes da dieta.

O nível de inclusão de cal influenciou $(\mathrm{P}<0,05)$ o volume urinário e a excreção urinária de ácido úrico. Efeito linear decrescente $(\mathrm{P}<0,05)$ do nível de inclusão de cal sobre o volume urinário (Tabela 5), pode estar relacionado com a redução no consumo de $\mathrm{MO}$ (6,0; 5,88 e 5,21 kg/dia) com a inclusão de cal (Tabela 2).

Esses volumes urinários encontram-se no intervalo relatado por Barbosa et al. (2006), os quais reportaram variação de 3,74 a 8,18 L/dia, quando utilizaram animais Nelores de diferentes categorias alimentados com dietas contendo dois níveis de concentrado (25 e 50\% MS da dieta).

Os valores de excreção urinária diárias de alantoína e purinas totais (mmol/dia) obtidos neste trabalho variaram de 72,84 a 97,18 e de 79,49 a 107,6, respectivamante(Tabela 5). Esses valores estão próximos aos encontrados por Barbosa et al. (2006), os quais reportaram uma variação de 58,73 a 92,33 mmol/dia para alantoína e de 62,66 a 102,16 mmol/dia para purinas totais, respectivamante.

Segundo Gonzalez \& MacLeod (1976), a fermentação espontânea da cana-de açúcar, que ocorre logo após a sua trituração em pequenos pedaços, pode conduzir à conversão de metade dos açúcares solúveis em ácidos orgânicos. Embora esses produtos finais possam ser metabolizados pelos animais, eles possuem pouco valor nutritivo para os microrganismos ruminais, assim, o processo de fermentação da cana-de-açúcar pode reduzir a síntese microbiana ruminal (Alvarez et al., 1977). Contudo, não foram observados efeitos dos tempos de exposição da cana-de açúcar à cal sobre a síntese de PBMic, quando as mesmas foram estimadas utilizando a excreção urinária de derivados de purinas (Tabela 5).

Os valores de síntese de PBMic encontrados nesse experimento, variaram de 360,3 a 506,9 g/dia. Esses valores foram superiores a variação de 208,2 e 339,9 g de PBMic/dia reportados por Barbosa et al. (2006). Contudo, os valores de excreção total de derivados de purinas na urina se assemelharam mais aos reportados por Barbosa et al. (2006). A explicação para este fato está no valor de excreção endógena de derivados de purinas utilizado nessa pesquisa de $0,170 \mathrm{mmol} / \mathrm{kg}$ de PV 0,75 (Osuji et al., 1996) e aquele utilizado por Barbosa et al. (2006) de 0,385 mmol/kg de PV ${ }^{0,75}$ (Verbic et al., 1990).Segundo Chen \& Ørskov (2003), para animais zebuínos devem ser considerados valores de derivados de purinas endógenos inferiores $(0,170 \mathrm{mmol} / \mathrm{kg}$ de $\mathrm{PV}^{0,75}$ ) aos $0,385 \mathrm{mmol} / \mathrm{kg}$ de $\mathrm{PV}^{0,75}$ sugeridos por estes autores para animais taurinos. Possivelmente, a utilização do valor de excreção endógena determinado em animais taurinos de $0,385 \mathrm{mmol} / \mathrm{kg}$ de $\mathrm{PV}^{0,75}$ pode resultar em

Tabela 5 - Excreção urinária de derivados de purinas e síntese microbiana em novilhas Nelore em crescimento

\begin{tabular}{|c|c|c|c|c|c|c|c|c|c|c|}
\hline Item & \multicolumn{2}{|c|}{ Tempo de exposição } & $\begin{array}{l}\text { Valor } \\
\text { de P }\end{array}$ & \multicolumn{3}{|c|}{ Cal } & $\begin{array}{l}\text { Desvio- } \\
\text { padrão }\end{array}$ & $\begin{array}{l}\text { Tempo de exposição } \\
\times \text { nível de cal }(P)\end{array}$ & \multicolumn{2}{|c|}{ Contraste $(P)$} \\
\hline Volume urinário & 6,63 & 10,15 & $<0,001$ & 10,29 & 7,50 & 7,39 & 2,11 & 0,69 & 0,02 & 0,14 \\
\hline Ácido úrico (mmol/dia) & 9,62 & 10,26 & 0,64 & 12,90 & 10,42 & 6,50 & 3,36 & 0,98 & $<0,01$ & 0,61 \\
\hline Purinas totais (mmol/dia) & 87,95 & 93,93 & 0,55 & 85,74 & 107,6 & 79,49 & 23,92 & 0,42 & 0,62 & 0,02 \\
\hline
\end{tabular}

PBMic = síntese ruminal de proteína bruta microbiana (g/dia) e EMNDT = eficiência de síntese de PBMic (g/kg de NDT). 
subestimação da síntese de PBMic ruminal em animais zebuínos, uma vez que esses animais possuem maior eficiência de utilização dos derivados de purinas endógenos em comparação aos taurinos (Chen \& Ørskov, 2003).

Não foram observados efeitos $(\mathrm{P}>0,05)$ dos tempos de exposição ou da inclusão de cal à cana-de-açúcar sobre a eficiência microbiana, expressa em relação à quantidade de NDT ingerido (Tabela 5). O valor médio de eficiência microbiana expresso em relação ao NDT ingerido foi de 123,0 g de PBMic/kg de NDT. Esse valor está próximo ao reportado por Veras et al. (2007), de 129,1 g de PBMic/kg de NDT, em experimento com dietas contendo aproximadamente $13 \%$ de $\mathrm{PB}$ na MS e compostas por 75\% de silagem de milho e 25\% de concentrado na MS. Também está próximo ao valor de 120,0 g de PBMic/kg de NDT sugerido por Valadares Filho et al. (2006b) como referência para as condições tropicais.

\section{Conclusões}

Considerando que a hidrólise da cana-de-açúcar com cal após três dias de armazenamento melhora a digestibilidade de alguns nutrientes, mas provoca redução do consumo total de nutrientes digestíveis e do ganho de peso, não se recomenda fornecer a cana-de-açúcar tratada com cal a novilhas Nelore em crescimento. Os indicadores dióxido de titânio e óxido de crômico são igualmente efetivos para estimar os consumos individuais de concentrado em bovinos alimentados em grupo. A cana-de-açúcar armazenada durante três dias sem qualquer tratamento não altera o desempenho de novilhas Nelore em crescimento.

\section{Referências}

ALLEN, M.S.; MERTENS, D.R. Evaluating constraints on fiber digestion by rumen microbes. The Journal of Nutrition, p.261-270, 1988.

ALLEONI, G.F.; BOIN, C.; BEISMANN, D.A. Utilização de diferentes suplementos no desempenho de bovinos alimentados com dietas básicas de cana-de-açúcar. Boletim da Indústria Animal, v.63, n.3, p.165-175, 2006.

ALVAREZ, F.J.; WILSON, A.; PRESTON, T.R. Effect of spontaneous fermentation of sugar cane on performance of zebu bulls. Tropical Animal Production, v.4, n.1, p.51-54, 1977.

BARBOSA, A.M.; VALADARES, R.F.D.; VALADARES FILHO. S.C. et al. Efeito do período de coleta de urina, dos níveis de concentrado e de fontes protéicas sobre a excreção de creatinina, de uréia e de derivados de purina e a produção microbiana em bovinos Nelore. Revista Brasileira de Zootecnia, v.35, n.3, p.870-877, 2006.

CHEN, X.B.; GOMES, M.J. Estimation of microbial protein supply to sheep and cattle based on urinary excretion of purine derivatives - an overview of technical details. International Feed Research Unit. Bucksburnd: Rowett Research Institute, 1992. 21p. (Occasional publication).

CHEN, X.B.; ORSKOV, E.R. Research on urinary excretion of purine derivatives on ruminants: past, present and future. United Kingdom: International Feed Research Unit, 2003. p.1-34.

DETMANN, E.; VALADARES FILHO, S.C.; PAULINO, M.F. et al. Avaliação da técnica de indicadores na estimação do consumo por ruminantes em pastejo. Cadernos Técnicos de Veterinária e Zootecnia, n.46, p.40-57, 2004.

FERREIRA, G.; MERTENS, D.R. Measuring detergent fiber and insoluble protein in corn silage using crucibles or filter bags. Animal Feed Science and Technology, v.133, p.335-340, 2007 (Short communication).

FUJIHARA, T.; ORSKOV, E.R.; REEDS, P.J. et al. The effect of protein infusion on urinary excretion of purine derivatives in ruminants nourished by intragastric nutrition. Jornal of Agricutural Science, v.109, p.7-12, 1987.

GONZALES, E.; MACLEOD, N.A. Spontaneous fermentation of sugarcane. Tropical Animal Production, v.1, p.80-85, 1976.

KAPS, A.; LAMBERSON, W. Biostatistics for animal science. Cambridge: CABI Publishing, 2004. 445p.

LOSADA, H.; ARANDA, E.; ALDERETE, R. et al. The voluntary intake by cattle of chopped sugar cane treated with sodium hydroxide. Tropical Animal Production, v.4, n.1, p.49-52, 1977.

MINOR, S.; HOVELL, S.D. Digestibility of sugarcane treated with sodium hydroxide. In: ANNUAL MEETING DOMINICAN CENTRE FOR LIVESTOCK RESEARCH WITH SUGAR CANE, 3., 1978, Santo Domingo, República Dominicana. Proceedings... Santo Domingo: Division de Ganaderia y Boyada del Consejo Estatal del Azúcar (CEAGANA), 1978.

MYERS, W.D.; LUDDEN, P.A.; NAYIGIHUGU, V. et al. Technical Note: A procedure for the preparation and quantitative analysis of samples for titanium dioxide. Journal of Animal Science, v.82, p.179-183, 2004.

NATIONAL RESEARCH COUNCIL - NRC. Nutrient requirements of dairy cattle. 7.ed. Whashington, D.C.: National Academic Press, 2001. 381p.

OLIVEIRA, M.D.S.; QUEIROZ, M.A.A.; CALDEIRÃO, E. et al. Efeito da hidrólise com $\mathrm{NaOH}$ sobre a digestibilidade "in vitro" da matéria seca da cana-de-açúcar (saccharum officinarum L.). Ars Veterinária, v.18, n.2, p.167-173, 2002.

ORTIZ-RUBIO, M.A.; ORSKOV, E.R.; MILNE, J. et al. Effects of different sources of nitrogen on in situ degradability and feed intake of zebu cattle fed sugarcane tops (Saccharum officinarum). Animal Feed Science and Technology, v.139, p.143-158, 2007.

OSUJI, P.O.; NSAHLAI, I.V.; KHALILI, H. Effect of fasting on the urinay excretion of nitrogen and purine derivatives by zebu (Bos Indicus) and crossbred (Bos indicus x Bos taurus) cattle. Journal Applied Animal Research, v.10, p.39-47, 1996.

PINA, D.S.; VALADARES FILHO, S.C.; AZEVEDO, J.A.G. et al. Níveis de inclusão e tempos de exposição do óxido de cálcio à cana-de-açúcar sobre parâmetros digestivos e fisíologicos de novilhas Nelore. Revista Brasileira de Zootecnia, v.39, n.7, p.1579-1586, 2010.

PINA, D.S.; VALADARES FILHO, S.C.; TEDESCHI, L.O. et al. Influence of different levels of concentrate and ruminally undegraded protein on the digestive parameters in beef heifers. Journal of Animal Science, v.87, p.1058-1067, 2009.

PONTES, R.A.M. Desempenho de ovinos alimentados com cana-de-açúcar in natura ou ensilada com óxido de cálcio. 2007. 75f. Dissertação (Mestrado em Zootecnia) - Universidade Federal de Viçosa, Viçosa, MG.

PRESTON, T.R. Nutritive value of sugarcane for ruminants Tropical Animal Production, v.2, n.2, p.125-142, 1977. 
SANTOS, M.C.; NUSSIO, L.G.; SOUSA, D.P. et al. Estabilidade aeróbia e perda de matéria seca de cana-de-açúcar in natura tratada com níveis crescentes de óxido de cálcio. In: REUNIÃO ANUAL DA SOCIEDADE BRASILEIRA DE ZOOTECNIA, 42., Goiânia, 2005. Anais... Goiânia: SBZ, 2005. (CD-ROM).

SILVA, D.J.; QUEIROZ, A.C. Análises de alimentos: métodos químicos e biológicos. 3.ed. Viçosa, MG: Universidade Federal de Viçosa, 2002. 235p.

STATISTICAL ANALYSES SYSTEM - SAS. SAS/STAT user's guide (Release 8.0), Cary: 1999. 329p.

TITGEMEYER; E.C.; ARMENDARIZ, C.K.; BINDEL, D.J. et al. Evaluation of titanium dioxide as a digestibility marker for cattle. Journal of Animal Science, v.79, p.1059-1063, 2001.

VALADARES, R.F.D.; GONÇALVES, L.C.; RODRIGUEZ, N.M. et al. Níveis de proteína em dietas de bovinos. 4. Concentrações de amônia ruminal e uréia plasmática e excreções de uréia e creatinina. Revista Brasileira de Zootecnia, v.26, n.6, p.1270-1278, 1997.

VALADARES, R.F.D.; BRODERICK, G.A.; VALADARES FILHO, S.C. et al. Effect of replacing alfalfa silage with high moisture corn on ruminal protein synthesis estimated from excretion of total purine derivatives. Journal of Dairy Science, v.82, n.12, p.2686-2696, 1999.
VALADARES FILHO, S.C.; MORAES, E.H.B.K.; DETMANN, E. et al. Perspectiva do uso de indicadores para estimar o consumo individual de bovinos alimentados em grupo. In: REUNIÃO ANUAL DA SOCIEDADE BRASILEIRA DE ZOOTECNIA, 43., 2006. João Pessoa. Anais... João Pessoa: SBZ, 2006a. p.291-322.

VALADARES FILHO, S.C.; PAULINO, P.V.R.; MAGALHÃES, K.A. Exigências nutricionais de zebuínos e tabelas de composição de alimentos BR-CORTE. Viçosa, MG: UFV, DZO, 2006b. 142p.

VERAS, R.M.L.; VALADARES FILHO, S.C.; AZEVEDO, J.A.G. et al. Níveis de proteína na dieta de bovinos Nelore de três condições sexuais: consumo, digestibilidades total e parcial, produção microbiana e parâmetros ruminais. Revista Brasileira de Zootecnia, v.36, n.4, p.1199-1211, 2007.

VERBIC, J.; CHEN, X.B.; MACLEOD, N.A. et al. Excretion of purine derivatives by ruminants. Effect of microbial nucleic acid infusion on purine derivative excretion by steers. Journal of Agricultural Science, v.114, n.3, p.243-248, 1990.

WILLIANS, C.H.; DAVID, D.J.; IISMA, O. The determination of chromic oxide in faeces samples by atomic absorption spectrophotometry. Journal of Agricultural Science, v.59, n.3, p.381-385, 1962. 